\title{
ON THE HOMOGENIZATION OF PARTIAL INTEGRO-DIFFERENTIAL-ALGEBRAIC EQUATIONS
}

\author{
MARCUS WAURICK
}

Abstract. We present a Hilbert space perspective to homogenization of standard linear evolutionary boundary value problems in mathematical physics and provide a unified treatment for (non-)periodic homogenization problems in thermodynamics, elasticity, electro-magnetism and coupled systems thereof. The approach permits the consideration of memory problems as well as differential-algebraic equations. We show that the limit equation is well-posed and causal. We rely on techniques from functional analysis and operator theory only.

Mathematics subject classification (2010): 74Q15, 35B27, 35Q74, 35Q61, 35Q79.

Keywords and phrases: Homogenization, partial differential equations, delay and memory effects, coupled systems, multiphysics, $G$-convergence.

\section{REFERENCES}

[1] G. Allaire And M. Briane, Multiscale convergence and reiterated homogenisation, Proc. R. Soc. Edinb., Sect. A, 126 (2): 297-342, 1996.

[2] M. AMAR, Two-scale convergence and homogenization on $B V(\Omega)$, Asymptotic Analysis, 16: 65-84, 1998.

[3] S. Bauer, D. Pauly, And M. Schomburg, The Maxwell Compactness Property in Bounded Weak Lipschitz Domains with Mixed Boundary Conditions, arXiv:1511.06697.

[4] G. Barbatis AND I. G. Stratis, Homogenization of Maxwell's equations in dissipative bianisotropic media, Mathematical Methods in the Applied Sciences, 26: 1241-1253, 2003.

[5] A. Bensoussan, J. L. Lions, and G. Papanicolaou, Asymptotic Analysis for Periodic Structures, North-Holland, Amsterdam, 1978.

[6] A. BRAIDES, Introduction to homogenization and Gamma-convergence, International Centre for Theoretical Physics, Trieste, 1993.

[7] A. BRAIDES, A handbook of Gamma-convergence, Elsevier, Amsterdam, 2006.

[8] M. BRiane, J. CASAdo-Díaz, AND F. Murat, The div-curl lemma "trente ans après": an extension and an application to the $G$-convergence of unbounded monotone operators, J. Math. Pures Appl., 91 (5): 476-494, 2009.

[9] D. Cioranescu And P. Donato, An Introduction to Homogenization, Oxford University Press, New York, 2010.

[10] F. Colombini And S. Spagnolo, On the convergence of solutions of hyperbolic equations, Commun. Partial Differ. Equations, 3: 77-103, 1978.

[11] M. COSTABEL, A remark on the regularity of solutions of Maxwell's equations on Lipschitz domains, Math. Methods Appl. Sci., 12: 365-368, 1990.

[12] B. Dacoragna, Direct Methods in the Calculus of Variations, Springer, Berlin, 1989.

[13] B. GustafsSON AND J. Mossino, A criterion for H-convergence in elasticity, Asymptotic Analysis, 51: 247-269, 2007.

[14] F. Jochmann, A compactness result for vector fields with divergence and curl in $L^{q}(\Omega)$ involving mixed boundary conditions, Appl. Anal. 66 (1-2): 189-203, 1997.

[15] A. Kalauch, R. Picard, S. Siegmund, S. Trostorff, and M. Waurick, A Hilbert Space Perspective on Ordinary Differential Equations with Memory Term, Journal of Dynamics and Differential Equations, 26 (2): 369-399, 2014. 
[16] P. KuHn, Die Maxwellgleichung mit wechselnden Randbedingungen, Dissertation, Universität Essen, Fachbereich Mathematik, http://arxiv.org/abs/1108.2028, 1999.

[17] D. Lukkassen, G. Nguetseng, and P. Wall, Two-scale convergence, International Journal of Pure and Applied Mathematics, 1: 35-86, 2002.

[18] R. D. MindLin, Equations of high frequency vibrations of thermopiezoelectric crystal plates, Int. J. Solids Structures, 10: 625-637, 1974.

[19] S. Mukhopadyay, R. Picard, S. Trostorff, And M. Waurick, On Some Models in Linear Thermo-Elasticity with Rational Material Laws, Mathematics and Mechanics of Solids, accepted, 2014.

[20] A. J. Mulholland, R. Picard, S. TrostorfF, And M. Waurick, On well-posedness for some thermo-piezo-electric coupling models, Math. Methods Appl. Sci., accepted, 2016.

[21] S. MüLLER, Homogenization of nonconvex integral functionals and cellular elastic materials, Arch. Rational Mech. Anal., 99: 189-212, 1987.

[22] F. Murat, H-convergence, Technical report, Séminaire d'analyse fonctionnelle et numérique de l'Université d'Alger, 1978.

[23] G. Nguetseng, A general convergence result for a functional related to the theory of homogenization, SIAM Journal on Mathematical Analysis, 20: 608-623, 1989.

[24] G. NGuetseng, Homogenization structures and applications, I, Z. Anal. Anwend., 22 (1): 73-107, 2003.

[25] G. Nguetseng, Homogenization structures and applications, II, Z. Anal. Anwend., 23 (3): 483-508, 2004.

[26] R. PICARD, An elementary proof for a compact imbedding result in generalized electromagnetic theory, Math. Z., 187: 151-164, 1984.

[27] R. PICARD, Evolution equations as operator equations in lattices of Hilbert spaces, Glas. Mat. Ser. III, 35: 111-136, 2000.

[28] R. PICARD, A structural observation for linear material laws in classical mathematical physics, Math. Methods Appl. Sci., 32: 1768-1803, 2009.

[29] R. Picard And D. McGhee, Partial Differential Equations: A Unified Hilbert Space Approach, Expositions in Mathematics, Vol. 55, DeGruyter, Berlin, 2011.

[30] R. Picard, S. Seidler, S. Trostorff, And M. Waurick, On Abstract grad-div Systems, J. Differential Equations, 260, 6 (2016) 4888-4917.

[31] R. Picard, S. Trostorff, And M. Waurick, On a Class of Boundary Control Problems, Oper. Matrices 8 (1): 185-204, 2014.

[32] R. PiCARD, S. TrostorfF, AND M. WAURICK, On evolutionary equations with material laws containing fractional integrals, Math. Meth. Appl. Sci., 2014. DOI: 10.1002/mma.3286.

[33] R. PICARD, N. WECK, AND K.-J. WitsCH, Time-harmonic Maxwell equations in the exterior of perfectly conducting, irregular obstacles, Analysis, 21: 231-263, 2001.

[34] R. Pichrd, S. Trostorf, M. Waurick, M. Wehows Ki, Non-Autonomous Evolutionary Problems, Journal of Evolution Equations, 13: 751-776, 2013.

[35] S. Spagnolo, Sulla convergenza di soluzioni di equazioni paraboliche ed ellittiche, Annali della Scuola Normale Superiore di Pisa, 22: 571-597, 1968.

[36] L. TARTAR, Compensated compactness and applications to partial differential equations, Nonlinear analysis and mechanics: Heriot-Watt Symp., Vol. 4, Edinburgh 1979, Res. Notes Math., 39: 136-212, 1979.

[37] L. TARTAR, The General Theory of Homogenization: A Personalized Introduction, Springer, Heidelberg, 2009.

[38] S. TrostorfF, Well-posedness and causality for a class of evolutionary inclusions, Dissertation, TU Dresden, http://www. qucosa.de/fileadmin/data/qucosa/documents/7832/phd-thesis_ trostorff.pdf, 2011.

[39] S. Trostorff AND M. WAURICK, A note on elliptic type boundary value problems with maximal monotone relations, Mathematische Nachrichten, 287 (13): 1545-1558, 2014.

[40] M. WAURICK, Limiting Processes in Evolutionary Equations - A Hilbert Space Approach to Homogenization, Dissertation, TU Dresden, http://nbn-resolving.de/urn:nbn:de:bsz:14-qucosa $-67442,2011$.

[41] M. WAURICK, A Hilbert space approach to homogenization of linear ordinary differential equations including delay and memory terms, Math. Methods Appl. Sci., 35 (9), 1067-1077, 2012. 
[42] M. WAURICK AND M. KALISKe, A Note on Homogenization of Ordinary Differential Equations with Delay Term, PAMM, 11: 889-890, 2011.

[43] M. WAURICK, Homogenization of a class of linear partial differential equations, Asymptotic Analysis, Asymptotic Analysis 82: 271-294, 2013.

[44] M. WAURICK, G-convergence of linear differential equations, Journal of Analysis and its Applications, 33 (4): 385-415, 2014.

[45] M. WAURICK, Homogenization in fractional elasticity, SIAM J. Math. Anal., 46 (2): 1551-1576, 2014.

[46] M. WAURICK, Homogenization in Fractional Elasticity - One spatial dimension, PAMM, 13: 521$522,2013$.

[47] M. WAURICK, On Non-Autonomous Integro-Differential-Algebraic Evolutionary Problems, Mathematical Methods in the Applied Sciences, 38 (4): 665-676, 2015.

[48] M. WAURICK, Continuous dependence on the coefficients for a class of non-autonomous evolutionary equations, TU Dresden, arXiv-preprint: http://arxiv.org/abs/1308.5566, 2013.

[49] M. WAURICK AND M. KALISKE, On the well-posedness of evolutionary equations on infinite graphs, Spectral Theory, Mathematical Sytem Theory, Evolution Equations, Differential and Difference Equations. Operator Theory: Advances and Applications, Birkhäuser, Basel, 221: 653-666, 2012.

[50] C. WeBer, A local compactness theorem for Maxwell's equations, Math. Methods Appl. Sci. 2: 12 $25,1980$.

[51] N. WECK, Maxwell's boundary value problem on Riemannian manifolds with nonsmooth boundaries, J. Math. Anal. Appl. 46: 410-437, 1974.

[52] N. WECK, Local compactness for linear elasticity in irregular domains, Math. Methods Appl. Sci., 17 (2): 107-113, 1994.

[53] N. Wellander, The two-scale Fourier transform approach to homogenization; periodic homogenization in Fourier space, Asymptotic Analysis, 62: 1-40, 2009.

[54] K.-J. WitsCH, A remark on a compactness result in electromagnetic theory, Math. Methods Appl. Sci., 16 (2):123-129, 1993.

[55] V. V. Zhikov, S. M. Kozlov, O. A. Oleinik, And K. T'En NgoAn, Averaging and Gconvergence of differential operators, Russian Mathematical Surveys, 34: 69-147, 1979. 